\begin{tabular}{|c|c|c|}
\hline PKS & REVISTA DE GEOGRAFIA & OJS \\
\hline $\begin{array}{l}\text { PUBLIC } \\
\text { KNOWLEDGE } \\
\text { PROJECT }\end{array}$ & $\begin{array}{c}\text { (RECIFE) } \\
\text { http://www.revista.ufpe.br/revistageografia }\end{array}$ & $\begin{array}{l}\text { OPEN } \\
\text { JOURNAL } \\
\text { SYSTEMS }\end{array}$ \\
\hline
\end{tabular}

\title{
TERRITÓRIO E ESPAÇO URBANO: UMA ANÁLISE SOBRE O PROCESSO DE FORMAÇÃO/EXPANSÃO DO BAIRRO SEMINÁRIO EM CRATO - CE
}

\author{
Bruno Ferreira Soares ${ }^{1}$, Suely Salgueiro Chacon ${ }^{2}$, Ivan da Silva Queiroz ${ }^{3}$, Francisca Laudeci \\ Martins Souza ${ }^{4}$
}

\begin{abstract}
${ }^{1}$ Doutorando do Programa de Pós-Graduação em Geografia da Universidade Federal de Pernambuco. Email: bruno.geografia@hotmail.com

${ }^{2}$ Professora do Centro de Ciências Agrárias da Universidade Federal do Ceará. Email: suelychacon@gmail.com

${ }^{3}$ Professor do Curso de Licenciatura em Geografia da Universidade Regional do Cariri. Email: isqz@hotmail.com

${ }^{4}$ Professora do Departamento de Economia da Universidade Regional do Cariri. Email: laudecimartins@yahoo.com.br
\end{abstract}

Artigo recebido em 15/08/2016 e aceito em 13/08/2017

\begin{abstract}
RESUMO
O presente estudo surge com a intenção de analisar o processo de formação e expansão do bairro Seminário, em Crato - CE, bem como de identificar os principais agentes produtores do recorte urbano em questão. A pesquisa enquadra-se na condição de estudo de caso, tendo como abordagem metodológica o método qualitativo. Diante disso, utilizou-se de uma interlocução com autores ligados a temática, no sentido de refletir em torno do conceito de território e dos elementos produtores do espaço urbano, além de uma análise documental referente aos aspectos sócioespaciais do caso em estudo e visitas de campo. Destaca-se como resultado a apresentação dos papéis exercidos pela Igreja Católica, pelo Estado e pelos grupos sociais excluídos na produção do bairro em foco.
\end{abstract}

Palavras-chave: Território; Espaço Urbano; Bairro Seminário.

\section{TERRITORY AND URBAN SPACE: AN ANALYSIS ABOUT THE PROCESS OF FORMATION/EXPANSION OF THE SEMINARIO DISTRICT IN CRATO - CE}

\begin{abstract}
This study intends to analyze the formation and expansion process of the Seminario district, located in Crato $\mathrm{CE}$; and to identify the main producing agents of this urban area. The research fits in the condition of case study, which has a qualitative method as a methodological approach. Therefore, an interlocution with authors related to the theme was implemented, aiming to generate a reflection around the concept of territory and urban space producing elements; in addition to a documentary analysis regarding the socio-spatial aspects of the case under study, and field visits. Thereby, it is highlighted as a result the presentation of the roles played by the Catholic Church, by the State and by the social groups excluded in the production of the analyzed district.

Key-words: Territory; Urban Space; Seminario Neighborhood.
\end{abstract}




\section{INTRODUÇÃO}

Elemento-chave, mas não exclusivo, da geografia o conceito de território está constantemente sendo repensado em virtude da polissemia que o envolve. Do ponto de vista da análise social, o território só se torna um conceito utilizável quando pensado juntamente com os atores que dele se utilizam, não se restringindo a noção de espaço concreto.

O espaço urbano, por sua vez, resulta de ações complexas e dinâmicas que exigem uma constante reorganização espacial e traduzem os interesses dos agentes dominantes. Ao Estado compete o papel de mediador dos conflitos que se apresentem do intrincado conjunto de usos da terra.

Localizado na cidade do Crato, no estado brasileiro do Ceará, o Seminário caracterizase como um bairro predominantemente residencial, de média densidade e padrão habitacional precário. Sua origem está diretamente ligada ao crescimento econômico vivenciado pelo município e seu processo de urbanização, materializando-se na fundação do primeiro estabelecimento de ensino superior do interior nordestino, bem como na exclusão socioespacial e na ocupação desordenada.

Partindo da premissa de que a produção do espaço urbano reflete a ação simultânea de diversos e complexos agentes sociais através do tempo, o objetivo do trabalho em foco é analisar o processo de formação e expansão do bairro Seminário em Crato - CE, identificando seus principais agentes produtores.

Para tanto, estruturou-se o trabalho de forma que inicialmente tentasse refletir em torno dos conceitos de território, espaço urbano e seus agentes sociais produtores. $\mathrm{Na}$ sequência, procurou-se realizar uma caracterização socioespacial do bairro em estudo.

Destarte, procedeu-se com a análise proposta, versando em torno do papel desempenhado pela Igreja Católica, o Estado e os grupos sociais excluídos, apresentando, por fim, as considerações referentes ao processo de formação e expansão do recorte urbano em questão.

\section{PROCEDIMENTOS METODOLÓGICOS}

No que concerne a metodologia utilizada, a pesquisa possui um caráter qualitativo e enquadra-se na condição de estudo de caso, que, segundo Yin (2005), é a estratégia ideal quando o foco reside em avaliar um fenômeno contemporâneo em seu contexto real. Quanto 
ao tipo de pesquisa, o estudo pode ser caracterizado como exploratório-descritivo. Na medida em que busca proporcionar maior aproximação com o problema, bem como descrever o fenômeno e estabelecer variáveis (GIL, 2010).

O bairro Seminário em Crato - CE, foi escolhido como lócus e objeto da pesquisa em virtude de ter uma população superior à de muitos municípios que integram a Região Metropolitana do Cariri - RMC, e por ter sido submetido a um projeto do Governo do Estado do Ceará que pretende solucionar históricos problemas socioambientais.

Recorre-se ao passado na tentativa de compreender o presente. Assim, foi realizada uma revisão bibliográfica em que foram analisados livros e periódicos no intuito de qualificar a base teórica referente ao conceito de território, a produção do espaço urbano e seus agentes sociais produtores, bem como compreender o processo de formação do bairro em foco. Procedeu-se com uma análise documental objetivando realizar uma caracterização socioespacial do bairro, assim como conhecer os instrumentos reguladores do Projeto de Recuperação Ambiental e Urbanização do Bairro Seminário.

Destaca-se ainda a realização de visitas de campo ao bairro em foco e a instituições governamentais no intuito de obter maiores informações e materiais referentes a análise documental. Durante as visitas foi feito o registro fotográfico de aspectos considerados relevantes à pesquisa.

\section{O TERRITÓRIO}

O conceito de território surge na tradicional geografia como espaço concreto em si, apropriado por um grupo social e evoca a noção de território nacional, de Estado. Souza (2008) adverte para o fato de que esse conceito pode ser entendido também à escala nacional e em associação com o Estado, todavia não deve estar a essa escala reduzido. Para ele, os territórios existem e são construídos e desconstruídos em escalas temporais diversas e distintas.

Em Seabra; Carvalho; Leite (2000) o geógrafo Milton Santos ressalta que o território só se torna um conceito utilizável, do ponto de vista da análise social, a partir do momento em que o pensamos juntamente com os atores que dele se utilizam. Para ele a sociedade exerce um diálogo permanente com o território usado, que inclui as coisas naturais e artificiais, a herança social e a sociedade em seu movimento atual. 
Para Haesbaert (1998) o território terá sempre como uma de suas propriedades o assentamento, a ocupação de uma área, um certo grau de "enraizamento" (concreto e simbólico) do grupo social que ali se reproduz. Entretanto, o autor adverte para o fato de que isso não implica em "naturalizar" a relação do homem com o espaço, bem como a noção de território.

O território não se restringe a um espaço dominado (apropriado) no sentido políticoeconômico do termo, mas apresenta uma dupla face, como produto de uma relação desigual de forças, envolvendo o domínio ou controle político do espaço e sua apropriação simbólica. A dominação tende a originar territórios puramente utilitários e funcionais, sem que um verdadeiro sentido socialmente compartilhado e/ou uma relação de identidade com o espaço possa ter lugar (HAESBAERT, 1998).

Souza (2008) afirma que o território é fundamentalmente um espaço definido e delimitado por e a partir de relações de poder, essencialmente um instrumento de exercício de poder, um campo de forças, uma teia ou rede de relações sociais. Relações estas que se projetam no espaço, sobrepondo a noção de território como um simples espaço concreto.

\section{O ESPAÇO URBANO}

Ao enfatizar a necessidade de se distinguir os conceitos de cidade e urbano Lefebvre (2008) afirma que a principal diferença entre eles reside no fato de que o urbano aparece e se manifesta no curso da explosão, estilhaçamento da cidade. Para ele, é necessário que se pense um processo contínuo, uma periodização, que vai da cidade política ao urbano, passando pela cidade mercantil e pela cidade industrial (MONTE-MÓR, 2006).

A cidade política mantém seu domínio sobre o campo com a retirada do excedente produzido neste último, possibilitada por um aparato político-ideológico-militar (MONTEMÓR, 2006). Para Sposito (2014, p. 124), durante esse período “as interações espaciais estabeleciam-se a partir de cidades-Estado, ou seja, cada cidade comandava seu espaço rural, de onde provinha o excedente que a sustentava".

A cidade mercantil amplia a sua dominação sobre o campo, e resulta da gradativa entrada da burguesia na cidade, incentivada pelas feiras de artigos luxuosos, consolidando a economia de mercado (MONTE-MÓR, 2006). Para Lefebvre (2008, p. 83), até esse momento, "as cidades são e permanecem obras, e não produtos". 
Com a entrada da indústria na cidade a produção passou a se realizar no seio do espaço do poder, concentrar a classe trabalhadora e as condições de produção. O campo passa a depender da cidade para sua própria produção e consumo (MONTE-MÓR, 2006).

Para Henri Lefebvre (1999; 2008) e Monte-Mór (2006), a cidade industrial além de significar a subordinação total do campo à cidade, fez com que esta última também se transformasse em um produto industrial, sofrendo um processo de implosão-explosão, onde após elevada concentração de poder, capital, bens e pessoas sobre si, explode sobre os territórios circundantes, com a extensão do seu tecido urbano.

Assim, "o urbano é um terceiro elemento na oposição dialética cidade-campo, a manifestação material e socioespacial da sociedade urbano-industrial contemporânea, estendida, virtualmente, por todo o espaço social” (MONTE-MÓR, 2006, p. 14).

Corrêa $(1997 ; 1989)$ destaca a riqueza de abordagens com que se pode considerar o espaço urbano diante das características simultâneas que ele apresenta. Para o autor, o espaço urbano pode ser caracterizado como um complexo conjunto de usos distintos da terra, justapostos entre si. Esses usos diversos definem áreas igualmente diversas que, no entanto, mantém relações com as demais, ainda que sejam de naturezas e intensidades variáveis.

\section{A PRODUÇÃO DO ESPAÇO URBANO}

Como um produto social, o espaço urbano resulta das ações de agentes sociais concretos que o produzem e o consomem. Estas ações se acumulam e se engendram através do tempo de forma dinâmica e complexa, incluindo práticas que exigem um constante processo de reorganização espacial, e que, via de regra, refletem os interesses do agente dominante (CORRÊEA, 1989).

Para Brito e Deus (2009, p. 108), "analisar a produção do espaço urbano é deparar-se com o contexto de reprodução da vida em seus aspectos históricos, socioeconômicos, políticos e sociais”. Bahiana (1978) destaca as contribuições de Willian Form (1975), Horácio Capel (1972), Nora Clichevsky (1975), David Harvey (1973) e J. Borja (1975) para os estudos sobre os agentes modeladores e o uso do solo urbano.

Vasconcelos (1997) ressalta a existência de trabalhos mais recentes, como os de Durand-Lasserve (1986) e Corrêa (1989). O primeiro, limitando-se a questão fundiária, apresenta três atores-chave na produção do espaço urbano: os proprietários fundiários, os loteadores ou promotores fundiários e o produtor e promotor imobiliário, sendo o poder 
público tratado em separado. O segundo, a partir da realidade brasileira, apresenta como agentes produtores do espaço urbano: os proprietários dos meios de produção, os proprietários fundiários, os promotores imobiliários, o Estado e os grupos sociais excluídos.

Refletindo sobre a sua própria contribuição em relação a temática, Corrêa (2014, p. 47) destaca a existência de novos e velhos agentes sociais.

Bancos, companhias de seguros, empreiteiras, empresas ferroviárias e de bondes, fábricas têxteis, firmas comerciais e de serviços, proprietários fundiários, grupos de previdência privada, grupos sociais excluídos, indivíduos com investimentos e ordens religiosas participam, alguns há muito tempo, em maior ou menor intensidade, do processo de produção do espaço. [...] Ressalta-se aqui a produção de um "espaço vernacular", efetivada por aqueles que invadem e ocupam terras públicas e privadas, produzindo favelas, ou por aqueles que, no sistema de mutirão, dão conteúdo aos loteamentos populares das periferias urbanas. No processo de produção do "espaço vernacular", entram em cena novos agentes sociais, como aqueles ligados à criminalidade e ao setor informal de produção de imóveis.

Ciente dessa ressalva, como ponto de partida, o presente estudo fará uso dos agentes sociais produtores do espaço urbano propostos por Corrêa (1989), sendo estes:

Os proprietários dos meios de produção que, em função de suas atividades, são consideráveis consumidores de espaço, necessitando de amplos terrenos que satisfaçam os requisitos necessários às suas atividades, e ao mesmo tempo sejam de baixo custo.

Os proprietários fundiários, que apresentam interesses eminentemente ligados ao valor de troca e não de uso da terra, sempre com o objetivo de obterem maior renda fundiária de suas propriedades. "Estão particularmente interessados na conversão de terra rural em urbana, ou seja, têm interesse na expansão do espaço da cidade" (Corrêa, 1989, p.16).

Os promotores imobiliários, que possuem interesses convergentes aos dos proprietários fundiários e das indústrias de material de construção, buscam "produzir habitações com inovações, com valor de uso superior às antigas, obtendo-se, portanto, um preço de venda cada vez maior" (CORRÊA, 1989, p. 21).

O Estado, que atua de forma complexa, variando no tempo e no espaço, refletindo a dinâmica da sociedade da qual é parte e processando-se em três níveis: federal, estadual e municipal.

Vale salientar que este agente possui uma atuação mais perceptível no que tange a implantação de serviços públicos e a elaboração de leis relativas ao uso do solo. Todavia, "o Estado capitalista desempenha múltiplos papéis em relação à produção do espaço. Essa 
multiplicidade decorre do fato de o Estado constituir uma arena na qual diferentes interesses e conflitos se enfrentam" (CORRÊA, 2014, p. 45). Sua atuação tende a privilegiar os interesses dos segmentos da classe dominante.

E os grupos sociais excluídos, que correspondem a uma significativa parcela da população, na qual não possui renda suficiente para comprar um imóvel ou pagar o aluguel de uma habitação decente. Como alternativa, resta a estes grupos estabelecer moradia em cortiços, loteamentos periféricos, conjuntos habitacionais e favelas.

Por meio da ação dos próprios moradores ao longo do tempo, melhorando suas residências, e/ou pressionando o Estado para que atue na implantação de serviços de infraestrutura, a favela pode vir a se tornar um bairro popular. "Esta urbanização, contudo, desencadeia uma valorização que acaba por expulsar alguns de seus moradores e atrair outros" (CORRÊA, 1989, p. 31).

A esse respeito, é possível mencionar como exemplo os estudos de Dos Anjos e Lacerda (2015), ao analisarem os impactos socioambientais oriundos da dinamização do mercado de aluguel no bairro Brasília Teimosa, na cidade do Recife - PE.

Com origem na ocupação de terras, a área em questão tem sido caracterizada por uma série de intervenções urbanas promovidas pelo Estado. Embora seja inegável a constatação de que tais intervenções tenham elevado a qualidade ambiental da área - por meio de melhorias relacionadas a infraestrutura - há que se reconhecer que as melhorias contribuíram diretamente para sua valorização e com o intenso mercado habitacional de locação (DOS ANJOS; LACERDA, 2015).

\section{O MUNICÍPIO DO CRATO}

Localizado no estado brasileiro do Ceará, mais especificamente ao sul desse estado, o município do Crato limita-se: ao norte, com os municípios de Caririaçu e Farias Brito; ao sul, com o município de Barbalha e o estado do Pernambuco; a leste, com os municípios de Barbalha, Juazeiro do Norte e Caririaçu; e a oeste, com os municípios de Nova Olinda, Santana do Cariri e o estado do Pernambuco (IPECE, 2015).

O Crato possui uma população de 127.657 habitantes (IBGE, 2014) dos quais 16,89\% correspondem a população residente em área rural, e $83,11 \%$ correspondendo a população 
residente em área urbana (IPECE, 2015). Sendo composto por 10 distritos e 20 bairros ${ }^{1}$ (CRATO, 2005).

Figura 1 - Região Metropolitana do Cariri - RMC

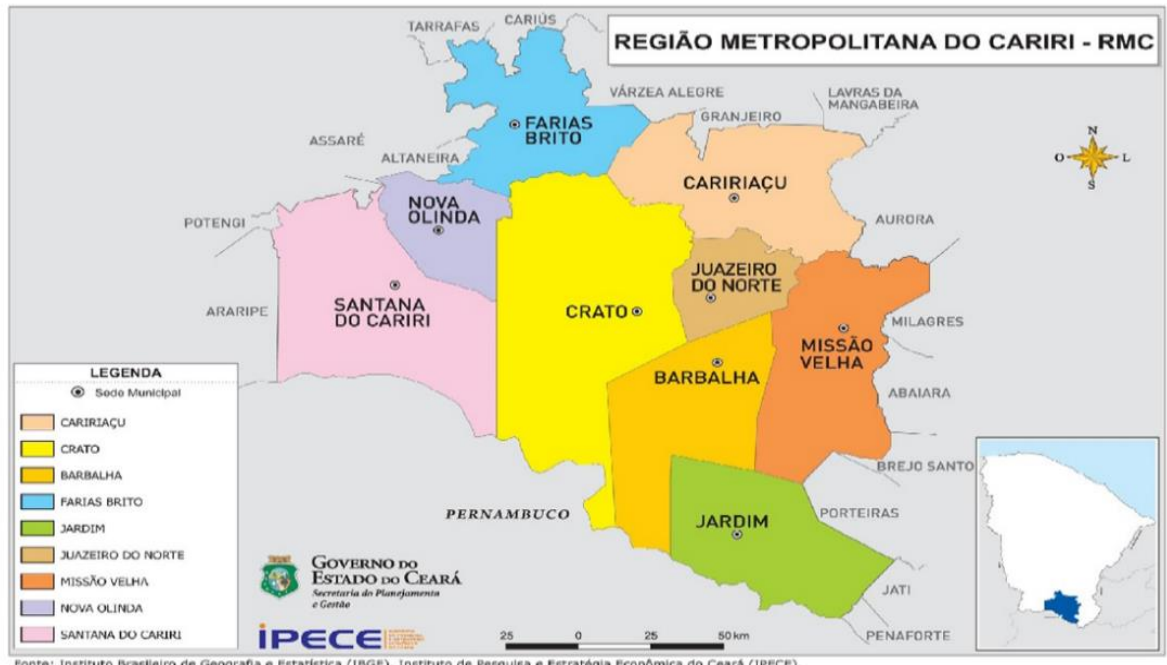

Fonte: Instituto de Pesquisa e Estratégia Econômica do Ceará IPECE (2009).

Somados aos municípios de Caririaçu, Farias Brito, Jardim, Missão Velha, Nova Olinda e Santana do Cariri; Crato, Juazeiro do Norte e Barbalha integram a Região Metropolitana do Cariri (Figura 1), criada pela Lei Complementar Estadual № 78 de 29 de junho de 2009.

\section{O BAIRRO SEMINÁRIO}

Denominado em virtude da presença do Seminário São José, fundado em 07 de março de 1875, o bairro Seminário está situado na colina entre o Rio Granjeiro e o Rio Batateira, em uma cota de 30m (PROEMA, 2014).

Devido a sua localização, o mesmo encontra-se em uma área privilegiada, possibilitando visualizar a cidade do Crato e o vale do cariri, no entanto, seu entorno é marcado pela degradação ambiental e pela ocupação indevida, o que coloca em risco a vida dos moradores, em especial dos que residem próximos às zonas atingidas pela erosão oriunda das águas da chuva e de esgotos (CEARÁ, 2013).

${ }^{1}$ O Plano Diretor Municipal destaca que, mesmo sendo esta a divisão oficial aprovada por lei, outras divisões são utilizadas popularmente e por alguns órgãos públicos, com destaque para a divisão estabelecida pelo Instituto Brasileiro de Geografia e Estatística - IBGE, que faz referência a existência de 30 bairros. 
Com uma população superior à de muitos municípios da Região Metropolitana do Cariri, o Seminário é o maior e mais populoso bairro do Crato. Segundo dados do IBGE, em 2009, estima-se que sua população passou à 30.000 habitantes $^{2}$ (PROEMA, 2014).

No ano de 2010, o bairro possuía catorze escolas, duas creches e três unidades de saúde. Quanto as atividades econômicas, o Seminário se caracteriza por pequenas atividades comerciais como mercearias, farmácias, magazine de roupas e papelarias (PROEMA, 2014), no entanto, destaca-se que próxima ao bairro está localizada a maior indústria da região, ligada ao setor de calçados e de materiais em EVA (CEARÁ, 2013).

O bairro em questão não conta com posto de segurança ou delegacia. As ocorrências mais frequentes estão diretamente ligadas a ingestão de bebidas alcoólicas e/ou ao consumo de drogas ilícitas. No tocante ao lazer, esporte e ao incentivo às práticas culturais, as políticas públicas ainda são escassas (PROEMA, 2014).

O Plano Diretor Municipal caracteriza o bairro Seminário da seguinte forma:

Com uso predominantemente residencial, de média densidade, padrão habitacional precário e desenho urbano de baixa qualidade, possui comércio eventual do tipo misto. A população sofre com a insuficiência de infraestrutura básica e social, espaços de lazer coletivo, praças e áreas verdes. A população ressente-se, também, de insegurança no bairro (CRATO, 2005, p. 139).

Recentemente, o bairro foi submetido a um projeto do Governo do Estado do Ceará em parceria com o Banco Mundial, onde foram realizados serviços de terraplanagem, muros de arrimo, drenagem e pavimentação do sistema viário, iluminação, contenção da encosta, projetos hidrosanitários, além da instalação de equipamentos públicos.

\section{ANÁLISE DO PROCESSO DE FORMAÇÃO E EXPANSÃO DO BAIRRO}

Até então Missão do Miranda, o Crato tornou-se vila em 1762, sendo instalada em 21 de junho de 1764, já como Vila Real do Crato. Para Farias Filho (2007, p. 75) o processo de formação de uma estrutura urbana foi lento, "a criação do gado e o cultivo da cana-de-açúcar

\footnotetext{
${ }^{2}$ Embora exista a divisão político administrativa do Seminário em outros bairros, é comum (principalmente à população) considerar toda a área como bairro Seminário, sendo o restante, comunidades integradas a ele. Acredita-se que o Relatório de Impacto Ambiental - RIMA do Projeto de Recuperação Ambiental e Urbanização do referido bairro tenha utilizado essa mesma lógica para determinar o contingente populacional do mesmo.
} 
eram a base da economia local. Nenhuma dessas atividades econômicas deu suporte para a criação de uma verdadeira urbanização".

Assim, até a primeira metade do século XIX, o Crato permanece como uma cidade pequena e de construções irregulares, contando, em 1838, com uma população de 2.000 habitantes (CRATO, 2005). Entretanto, em virtude das condições naturais da região, e do Crato em especial, rica em recursos hídricos, os fluxos migratórios de sertanejos fugindo das secas eram constantes (FARIAS FILHO, 2007).

Como consequência do incremento populacional a agricultura e o comércio se desenvolviam, passando o Crato a ser o principal produtor e fornecedor de alimentos para o sertão, e estabelecer importantes ligações comerciais com Recife, na época, o principal porto nordestino (FARIAS FILHO, 2007).

Paralelo a isso, a chegada de comerciantes de Icó, que faziam a conexão AracatiCrato, foi responsável por um surto comercial no município. Deriva dessa relação a primeira mudança de uso do solo no Crato, com antigas casas dando lugar a mercearias, lojas, cafés e boticas (CRATO, 2005).

\section{O PAPEL DA IGREJA CATÓLICA}

Corrêa (1997), ao apresentar as dimensões de análise de redes geográficas, ressalta que o Estado, as empresas, as instituições e os grupos sociais, são agentes sociais que podem influenciar na composição destas. Em relação às instituições o autor destaca, entre outras, a Igreja Católica, as dioceses e paróquias.

Vasconcelos (1997), por sua vez, afirma que os agentes modeladores das cidades no período colonial foram: a igreja, as ordens leigas, o Estado, os agentes econômicos e a população e os movimentos sociais. Para ele, as divisões promovidas pela igreja em relação as sedes paroquiais e as freguesias repercutem até o presente, sob a forma de divisões administrativas das cidades.

Em relação ao papel da Igreja na estruturação das cidades coloniais, o autor destaca que os conventos (seminários) desempenharam importante papel na expansão urbana colonial, pois localizavam-se nas periferias, nos finais de eixo urbano, e atraiam o crescimento da cidade em sua direção. 
Figura 2 - Vista aérea do Seminário São José e de parte do bairro Seminário

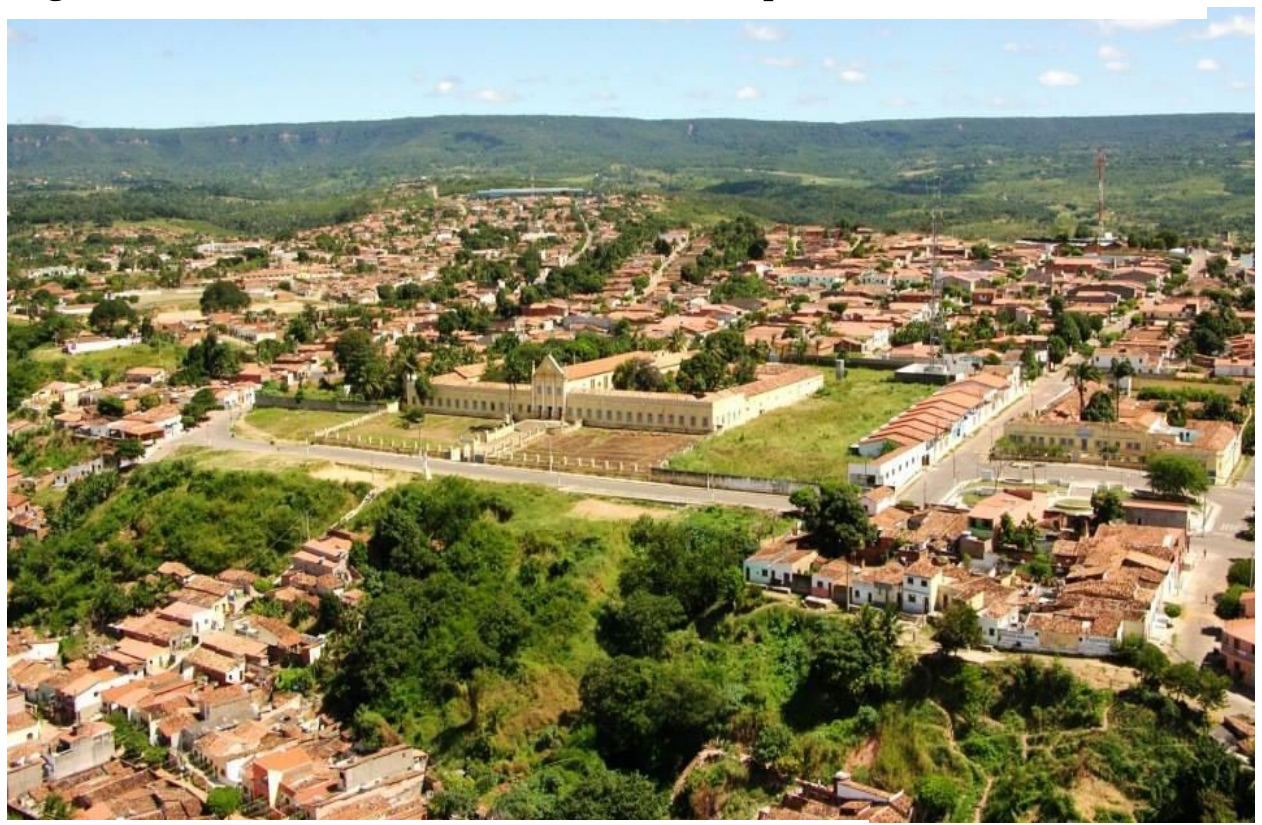

Fonte: Maia (2014).

Inaugurado em 07 de março de 1875, o Seminário São José (Figura 2) foi o primeiro estabelecimento de ensino religioso e superior do interior nordestino (SILVA; PEREIRA, 2005). Até a segunda metade do século XIX, o desenvolvimento urbano da cidade estava restrito ao baixio do Rio Grangeiro, entre os morros do Seminário e do Barro Vermelho. Com a inauguração do Seminário São José, localizado no alto do Grangeiro, a cidade do Crato "superou a barreira física do morro e subiu o Alto do Seminário, sem, entretanto, manter o traçado ordenado encontrado no centro". (CRATO, 2005, p. 31).

Figueiredo Filho e Pinheiro (1953, p. 45), destacam o crescimento populacional vivenciado pelo Crato e o seu processo de urbanização. Segundo eles, "de dia para dia, porém, amplia-se e embeleza-se a área urbana, com novos bairros e modernas residências, enquanto na periferia se disseminam os mocambos de taipa, com piso de terra batida".

A esse respeito, merecem destaque as contribuições de Moreira e Trevizan (2005, p. 81) ao afirmarem que:

A concentração da riqueza, característica própria do sistema (capitalista), e a expansão urbana não planejada levam à supervalorização de alguns espaços, forçando a retirada deles aqueles que não conseguem caminhar pari passu com este processo. Por sua vez, estes se deslocam desbravando espaços ainda não tão valorizados. É nessa lógica que atuam as migrações rural-urbanas e intra-urbanas. 
$\mathrm{Na}$ área da cidade onde estava situado o Seminário São José, no início do século XX, além das estruturas referentes ao prédio da diocese, foram construídas algumas casas de palha no lado sul do referido prédio (Figura 3).

Figura 3 - Encosta do Seminário em 1941

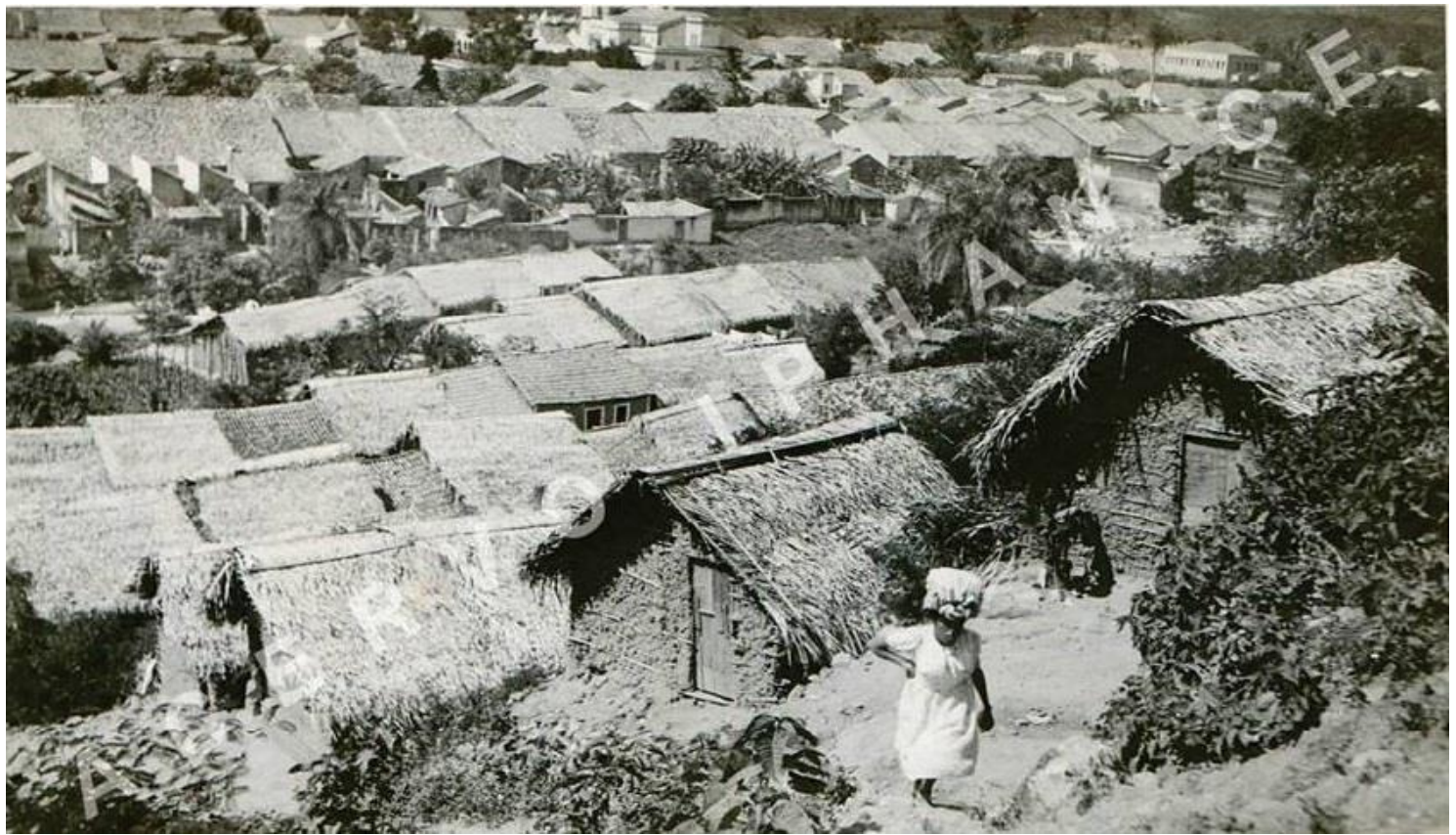

Fonte: IPHAN/Arquivo do Departamento Histórico Diocesano Pe. Gomes.

Com o tempo, essas casas foram se multiplicando, tendo em comum o fato de serem desprovidas de pavimentação e demais serviços públicos (SILVA; PEREIRA, 2005).

Em relação a esse processo, o Plano Diretor Municipal (CRATO, 2005, p. 32) destaca que:

Ao mesmo tempo, as classes mais abastadas da população buscam o afastamento pelo lado oeste, subindo o Morro do Granjeiro e ocupando grandes loteamentos (surgem o Sossego, Ossian Araripe e Parque Grangeiro) e as classes mais baixas instalam-se nos altos do Seminário, Vila Alta, Alto da Penha, muitas vezes ocupando as encostas e áreas de risco.

Nos anos quarenta, do século XX, com uma relativa melhoria nos serviços de abastecimento de água e no fornecimento de energia elétrica, o bairro em questão passou a atrair novos moradores. Em 1950 a Diocese fundou, no bairro, o Liceu Diocesano de Artes e Ofícios do Crato, com a finalidade de atender menores necessitados através de educação infantil e formação profissionalizante (SILVA; PEREIRA, 2005). 
No final da década de 1960, o Instituto Nacional de Desenvolvimento Agrário (INDA) e a Fundação Padre Ibiapina organizaram um Conselho de Moradores do Bairro. Entre os objetivos estava o de despertar para a organização comunitária, identificar problemas sociais e buscar soluções. "Com a colaboração de alguns religiosos, vinte e um líderes de ruas fundaram, em pleno Natal de 1969, a Sociedade Pró-Melhoramento do Bairro Seminário" (SILVA; PEREIRA, 2005, p. 26).

Oliveira Filho e Mitidiero Junior (2014) destacam a importante contribuição da Igreja Católica aos movimentos sociais no Brasil, em especial através das Comunidades Eclesiais de Base - CEBs. Destacam ainda que na cidade do Crato, especialmente no bairro Seminário, as CEBs desempenharam relevante papel na consolidação de lutas sociais ligadas, principalmente, a questão da moradia entre os anos de 1980 e 1990.

Destacam, entretanto, a contradição existente no fato de que grande parte dos terrenos ocupados no bairro Seminário durante esse período serem pertencentes à Diocese Cratense. "Isso referenciou vários conflitos internos dentro da Igreja, principalmente entre as alas progressistas e conservadoras" (OLIVEIRA FILHO; MITIDIERO JUNIOR, 2014, p. 47).

\section{O PAPEL DO ESTADO}

Corrêa $(2014 ; 1989)$ destaca a multiplicidade de papéis desempenhados pelo Estado na produção do espaço urbano. Segundo ele, o Estado pode atuar diretamente como grande industrial, consumidor de espaço, proprietário fundiário, promotor imobiliário, provedor de serviços públicos, sem deixar de ser agente de regulação do uso do solo e alvo dos movimentos sociais urbanos.

Em 1966, no bairro Seminário, foi inaugurado o Grupo Escolar Coronel Virgílio Távora, em homenagem ao então governador do estado do Ceará. Em 1974, o bairro recebe o Centro Comunitário Governador César Cals, uma parceria entre o Governo do Estado do Ceará e a Prefeitura Municipal do Crato (SILVA; PEREIRA, 2005).

Em 1978, através de um convênio que envolveu as três esferas de poder (federal, estadual e municipal), foi inaugurado no bairro a Escola de $1^{\circ}$ Grau Polivalente Governador Adauto Bezerra, destinada ao ensino profissionalizante. Silva e Pereira (2005) ressaltam que a instituição contribuiu com o crescimento educacional e profissional da população local, além de proporcionar o povoamento e a expansão de ruas. 
É necessário destacar ainda que o estabelecimento da referida instituição, envolveu, além das três esferas de poder, a Diocese do Crato.

\begin{abstract}
A gestão de Pedro Felício adquiriu no Bairro Seminário, através de uma permuta com o bispo Dom Vicente de Matos, um terreno medindo $26.580 \mathrm{~m}^{2}$. [...] a Diocese cedeu o terreno mediante troca por outro, medindo $16.000 \mathrm{~m}^{2}$, entestando com o Tiro de Guerra 10-004 mais um acréscimo de vinte e dois mil cruzeiros (SILVA; PEREIRA, 2005, p. 28).
\end{abstract}

Corrêa (1989, p. 27) adverte para o fato de ser uma tradição latino-americana a criação de núcleos urbanos a partir do zero pelo planejamento estatal. E alerta para o fato de que "a segregação residencial pode resultar também de uma ação direta e explicita do Estado através de planejamento".

O autor destaca ainda que uma das estratégias dos promotores imobiliários é contar com a ajuda do Estado para viabilizar a construção de residências para as camadas populares. Órgãos como o Banco Nacional da Habitação (BNH) e as Cooperativas de Habitações (COHABs) foram criados com esse intuito, assim como mecanismos jurídicos e financeiros como o Fundo de Garantia por Tempo de Serviço - FGTS (CORRÊA, 1997). Para ele,

Esta estratégia é viável em razão da importância da produção de habitações na sociedade capitalista. Cumpre ela um papel fundamental, que é o de amortecer as crises cíclicas da economia através do investimento de capital e da criação de numerosos empregos (CORRÊA, 1989, p. 23).

Construído em 1981, e financiado pelo Sistema Nacional de Habitação (SNH), o Conjunto Residencial Novo Crato contribuiu de forma significativa para a expansão do bairro Seminário. A população que se estabeleceu no conjunto era oriunda de outros bairros da cidade o que contribuiu também com o acréscimo populacional na área.

Em 1985, próximo ao conjunto Novo Crato, foi construído o Conjunto do IPEC, com casas financiadas pelo Instituto de Previdência do Estado do Ceará para atender aos funcionários estaduais (SILVA; PEREIRA, 2005).

Vale salientar que nas cidades onde a atividade industrial é expressiva, uma das estratégias dos proprietários industriais é a criação de amplas áreas fabris, se distanciando das áreas nobres da cidade e se aproximando das proletárias. "Deste modo, a ação deles modela a cidade, produzindo seu próprio espaço e interferindo decisivamente na localização de outros usos da terra" (CORRÊA, 1989, p. 15). 
Assim, a chegada da Indústria de Calçados Grendene no bairro Seminário, atraída por benesses estatais, por volta de 1996, provocou significativos impactos no bairro e na cidade. Inicialmente, a referida empresa gerou cerca de 2.000 empregos, impactando diretamente na economia, no contingente populacional, e na infraestrutura do bairro, bem como fomentando impactos ambientais.

“Com olho nos interesses empresariais e nos problemas da população, em algumas ruas do bairro, as autoridades municipais investiram em pavimentação e criaram uma linha de ônibus" (SILVA; PEREIRA, 2005, p. 42). Posteriormente, foram construídos mais dois conjuntos habitacionais, agora, em direção a indústria. Os conjuntos Vitória Nossa e o Nova Conquista abrigaram pessoas oriundas de outras partes da cidade e de municípios vizinhos.

\section{OS GRUPOS SOCIAIS EXCLUÍDOS}

As diferenças sociais inerentes ao sistema capitalista no que tange ao acesso a bens e serviços não são exclusividade dos países da América Latina, no entanto, apresentam-se ainda mais profundas nessa parte do continente. Entre os muitos sintomas da exclusão social está a ausência de moradia digna e/ou própria (CORRÊA, 1989).

Corrêa (1989) destaca que como alternativa à população desprovida de moradia resta a possibilidade de residir em cortiços próximos aos centros das cidades, as construções em regime de mutirão localizadas em loteamentos periféricos, os conjuntos habitacionais produzidos pelo Estado e geralmente distantes do centro, ou atuarem como agentes efetivos na produção do seu próprio espaço.

No bairro Seminário há um histórico de resistência e sobrevivência ligado aos movimentos sociais. Sua configuração socioespacial está diretamente ligada a processos de ocupação e de lutas travadas ao longo do tempo, resultando em diversas comunidades dentro do Bairro. Entre os anos de 1980 e 1990, o bairro Seminário registrou, pelo menos, quatro ocupações (OLIVEIRA FILHO; MITIDIERO JUNIOR, 2014).

Em 1983, cerca de 150 famílias ocuparam as casas do Conjunto do IPEC, onde foram construídas 93 casas destinadas à funcionários públicos do estado. Oliveira Filho e Mitidiero Junior (2014) ressaltam que a ocupação tem origem no fato de as residências ficarem fechadas por dois anos após a sua construção em virtude da inexistência de critérios de seleção para as 93 famílias diante de um universo de 1.000 famílias inscritas. 
Por ordem do então prefeito municipal Walter Peixoto, a polícia foi autorizada a invadir as residências e expulsar as famílias (Figura 4). Aquelas em que algum membro era funcionário do estado do Ceará conseguiram se fixar no referido conjunto, enquanto as demais foram despejadas e sublocadas em outro conjunto habitacional (OLIVEIRA FILHO; MITIDIERO JUNIOR, 2014).

Em 1990, famílias de baixa renda, desprovidas de residência, ocuparam um terreno localizado atrás do Seminário São José, terreno este pertencente a Diocese (SILVA; PEREIRA, 2005). Cerca de 200 pessoas construíram barracas de palha ou plástico, representando o domínio sobre aquele espaço.

\section{Figura 4 - Momento em que a polícia chegou ao conjunto para expulsar os} militantes

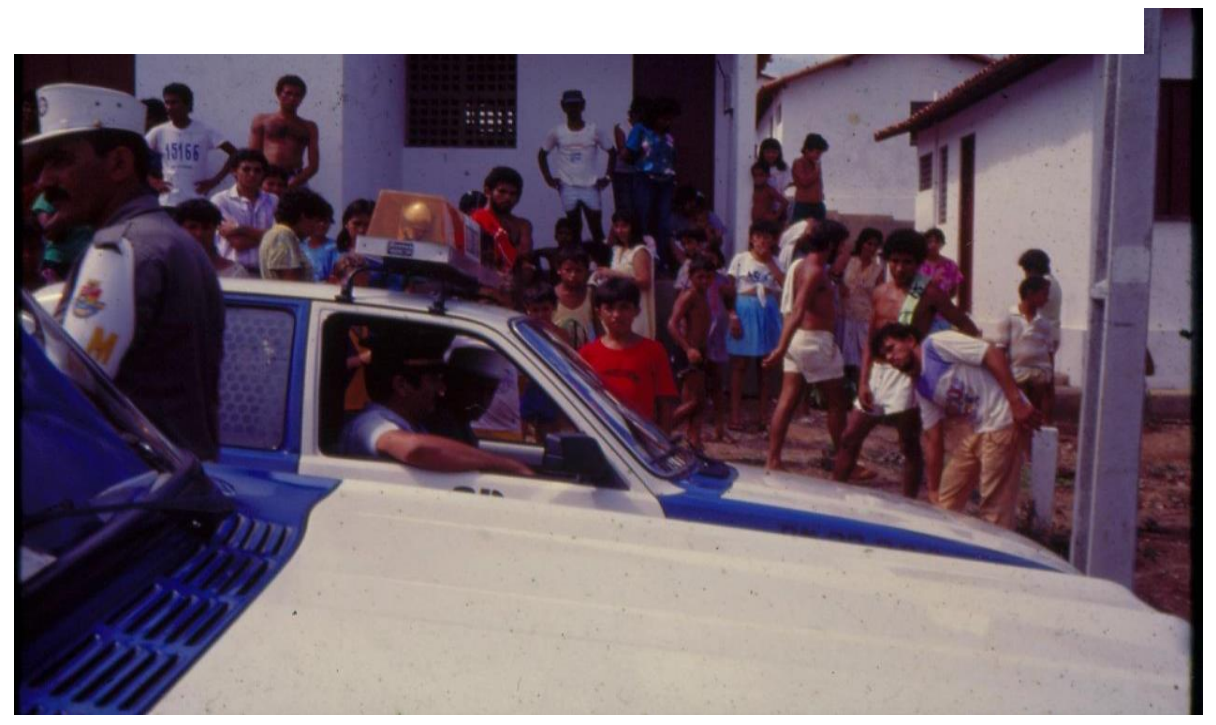

Fonte: Mara Guedes, 1983. Disponível em: Oliveira Filho; Mitidiero Junior (2014).

Como resultado, as famílias foram retiradas em troca de um terreno oferecido pela Prefeitura Municipal na periferia do Conjunto Novo Crato e nas Cacimbas. A Diocese logo tratou de lotear e vender o terreno que fora ocupado. Em 1996, mais uma ocupação ocorre no bairro, desta vez em um terreno pertencente a Prefeitura Municipal. Como resultado dessa nova ocupação, muitas pessoas conseguiram se estabelecer no local, enquanto outras comercializaram seus lotes (SILVA; PEREIRA, 2005).

Nesse lado da cidade, a ação dos Sem-teto acompanha a trajetória delineada pela expansão do bairro. [...] nos últimos anos, o movimento expandiu-se na direção sul, onde um contingente de famílias transferidas de outros bairros, construía em regime de mutirão, o Conjunto Vitória Nossa. Após a definição dessa área, o movimento 
social popular gerou os conjuntos N.S. da Penha e Nova Conquista (SILVA; PEREIRA, 2005, p. 36).

Em 2004, as ocupações tornam a ocorrer. Mais uma vez, o terreno ocupado pertencia a Prefeitura Municipal, localizando-se nas proximidades do Riacho das Piabas. "Lá, as pessoas lotearam a área, construíram barracas e iniciaram alicerces enquanto reivindicavam uma decisão favorável” (SILVA; PEREIRA, 2005, p. 36).

\section{O ESTADO VOLTA À CENA}

O processo de expansão em todas as direções, fez surgir no bairro deformações de suas características geoambientais. Para Moreira e Trevizan (2005, p. 79-80) impactos como esse se devem ao fato de que:

\footnotetext{
Com raras exceções, o poder público costuma atuar de forma discriminatória, em favor das áreas nobres ou centrais das cidades. Não se priorizam as necessidades da população periférica. Consequentemente, a luta pela sobrevivência leva as categorias sociais menos favorecidas a buscarem nos recursos naturais saídas improvisadas para atenderem as necessidades básicas, tais como, habitação, alimentação, necessidades fisiológicas, entre outras. Consequentemente constroemse espaços fortemente impactados, especialmente do ponto de vista natural e social.
}

Com uma ocupação feita de forma desordenada, o bairro em questão apresenta uma alta densidade de construções e população. No entanto, não dispõe de infraestrutura em esgotamento sanitário, algumas de suas vias não são pavimentadas, além de apresentar uma alta susceptibilidade aos azares geomorfológicos (RIBEIRO; GUERRA, 2003).

"Uma voçoroca (Figura 5) provocada por uma concentração de fluxo superficial oriundo de um canal de recolhimento de águas provenientes dos esgotos das residências, cresce com taxa média de 1 metro por ano" (RIBEIRO; GUERRA, 2003, p. 02).

O Governo do Estado do Ceará, no intuito de resolver um histórico problema que tem origem na implantação de vias com ausência de soluções de drenagem adequadas, além das ocupações habitacionais que abrigam populações de baixa renda em trechos de encosta; lançou, em 2009, o Projeto de Recuperação Ambiental e Urbanização do Bairro Seminário (PROEMA; 2014). 
Figura 5 - Voçoroca popularmente conhecida como Vulcão ou Buraco do Vulcão

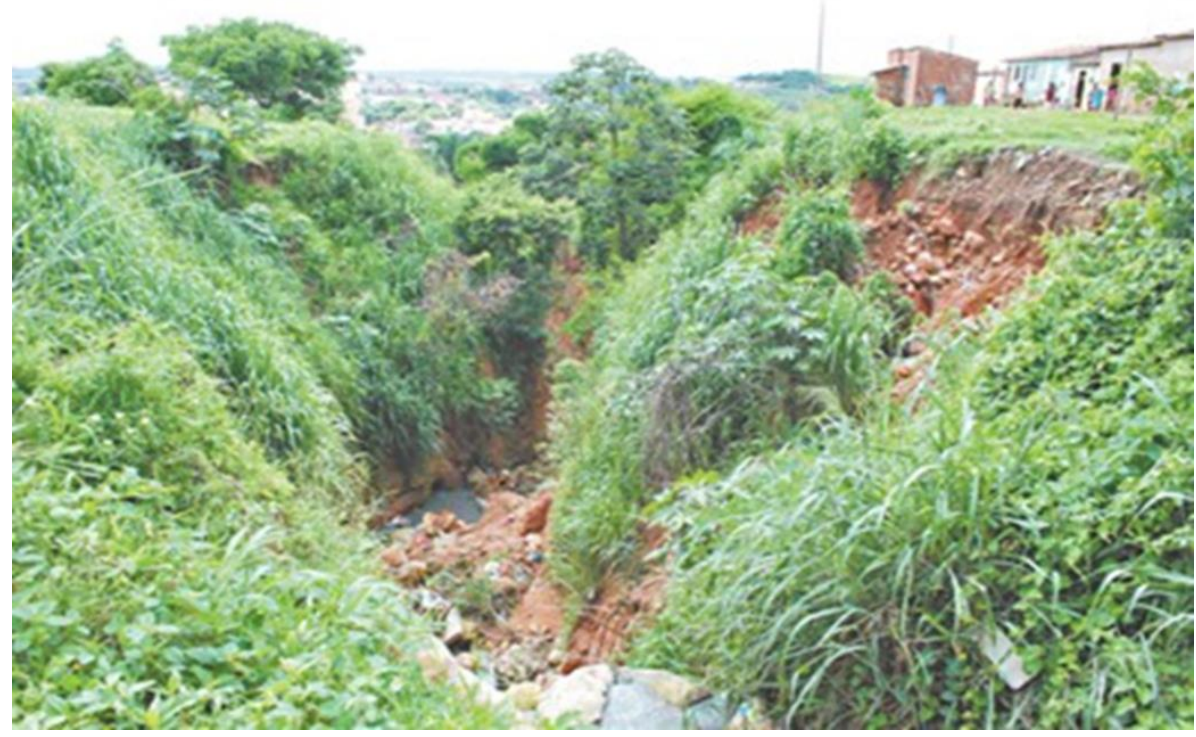

Fonte: Ceará (2010).

Foi executado na área, um projeto de urbanização no intuito de proporcionar espaços de lazer e paisagísticos reservados prioritariamente à pedestres e ciclistas; o controle do processo erosivo, através de obras de infraestrutura relacionadas à drenagem e escoamento de água (Figura 6); além da retirada dos imóveis considerados irregulares e em situação de risco (Figura 7).

Figura 6 - Intervenção realizada na voçoroca.

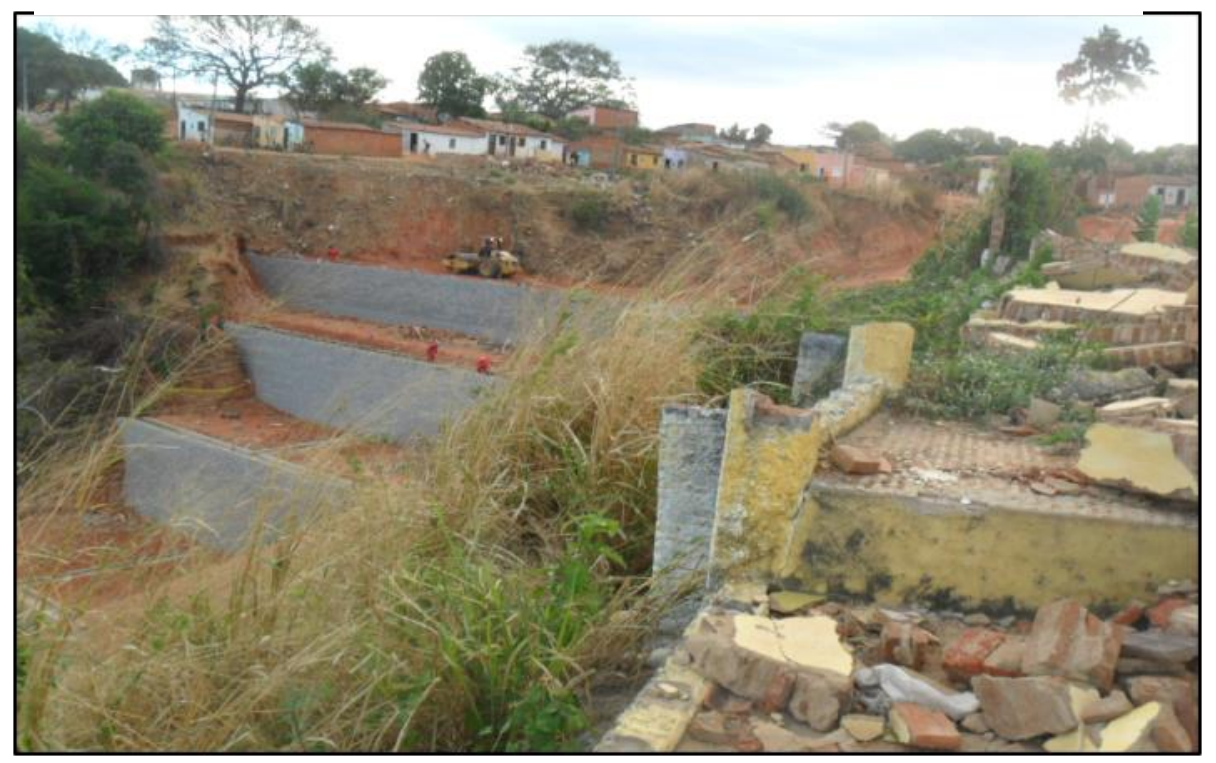

Fonte: Fotografia dos autores (2014). 
Figura 7 - Imóveis localizados na margem da voçoroca, demarcados com "X" informando que serão retirados em virtude do projeto.

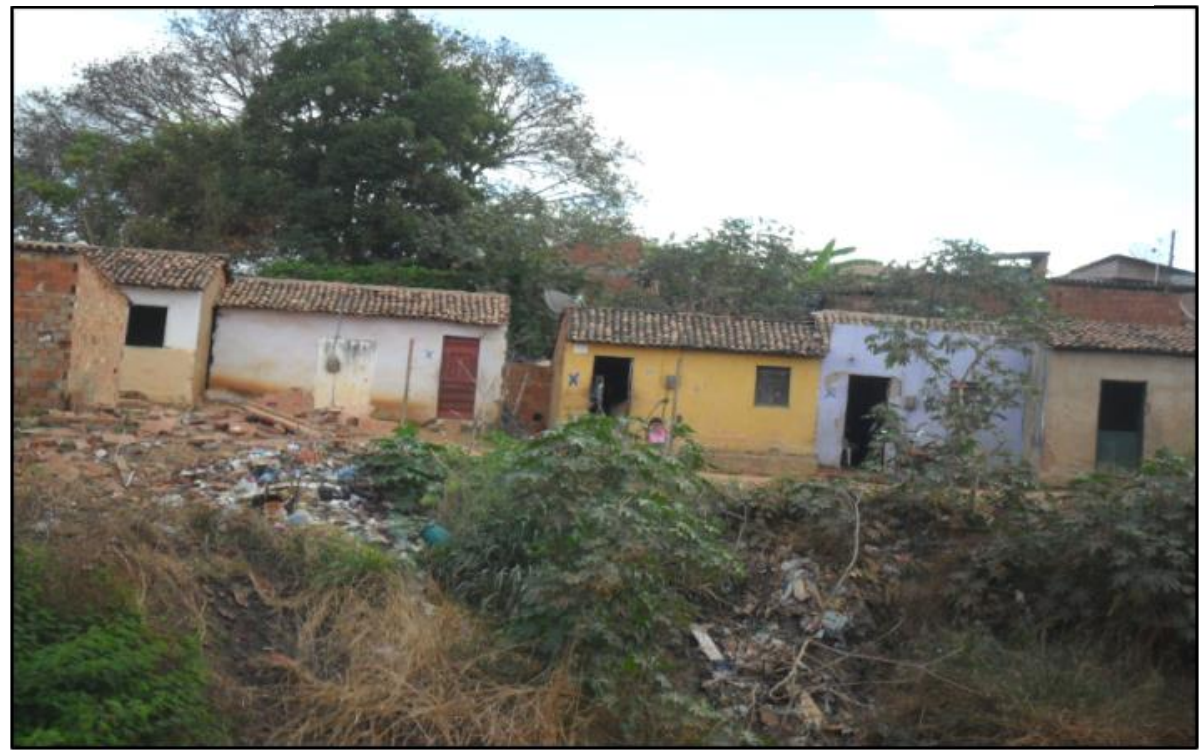

Fonte: Fotografia dos autores (2014).

Cernea e Macdowell (2000) destacam o fato de ser inegável a necessidade de implementação de ações que promovam a melhoria na qualidade de vida da população, gerem emprego e melhorem serviços. Entretanto, alertam que é igualmente inegável que, contraditoriamente, as mesmas obras e projetos que tem por objetivo promover o desenvolvimento, geram grandes problemas para seguimentos da população.

Harvey (2009) cita Manhattan, em Nova York, para afirmar que o direito das pessoas à cidade pode ser subtraído por meio de ações do mercado, por meio de ações ilegais e violentas, ou por meio de ações do governo. Corrêa (1989, p. 28) tomando como exemplo a abertura dos boulevards de Paris, e das grandes avenidas no Rio de Janeiro, destaca que:

Através de política conjugada de renovação urbana - abertura de modernas vias de tráfego - o Estado capitalista viabiliza simultaneamente vários interesses. De um lado, via expulsão dos pobres residentes em cortiços junto ao centro da cidade, redireciona a segregação residencial e viabiliza o capital imobiliário que tem oportunidade de realizar bons negócios [...] viabiliza também a ampliação do capital de empreiteiras e cria condições de uma circulação mais eficiente, viabilizando assim a produção de novos meios de transporte, entre eles aqueles de uso individual.

De acordo com o plano de reassentamento do projeto, 170 famílias foram afetadas, sendo que deste grupo, 107 famílias deverão ser retiradas de forma definitiva. Entre as políticas de atendimento ofertadas estava o reassentamento em conjunto habitacional. 
As opções de reassentamento propostas à população foram a de residirem em um conjunto habitacional localizado no próprio bairro, a cerca de 600 metros da área de intervenção do projeto e com 24 unidades habitacionais (apartamentos), ou residirem em um conjunto habitacional distando, aproximadamente, $5 \mathrm{Km}$ do centro do Crato, por sua vez, com 476 unidades habitacionais (casas).

A análise proposta pelo presente estudo balizou-se na asserção de Santos (SEABRA; CARVALHO; LEITE, 2000) ao destacar que o conceito de território só se torna utilizável quando pensado juntamente com os atores que dele se utilizam. Durante o processo de formação do bairro em foco, verifica-se a materialização das noções propostas por Corrêa (1997; 1989), quando afirma que o espaço urbano corresponde a um conjunto de usos distintos da terra, justapostos entre si, e que resultam da ação dinâmica e complexa de agentes sociais concretos através do tempo.

\section{CONSIDERAÇÕES FINAIS}

É possível destacar que a formação do bairro Seminário está diretamente ligada ao crescimento econômico e ao processo de urbanização do Crato, substancializados na fundação do primeiro estabelecimento de ensino superior do interior nordestino, e na exclusão socioespacial e ocupação desordenada.

Em relação aos elementos produtores do bairro, percebe-se uma multiplicidade de papéis exercidos pelos agentes envolvidos. A atuação da Igreja Católica pode ser considerada como determinante, pois versa desde a instalação do marco embrionário do bairro, o Seminário São José, até o exercício de proprietário fundiário e promotor imobiliário, pelo fato de ter sido uma das principais proprietárias de terras no local. Destaca-se ainda o papel exercido por essa instituição no tocante a assistência à população e ao incentivo à organização comunitária.

Como não poderia deixar de ser, o Estado (em sua multiplicidade de interpretações) foi, e continua a ser, fulcral na produção do espaço urbano em estudo. Esse agente exerceu, de acordo com a ocasião, papel de proprietário fundiário, promotor imobiliário, proprietário dos meios de produção, agente regulador do uso do solo, provedor (ou não) de serviços públicos, e alvo dos movimentos sociais. Além de ser o principal aliado dos proprietários dos meios de produção. 
Os grupos sociais excluídos podem ser apontados como exercendo um papel central para a produção/expansão do espaço urbano em foco. Estes, enxergaram nesse recorte espacial uma alternativa de sobrevivência, muitas vezes resultando na formação do que Corrêa (2014) classifica como um espaço vernacular. Por meio das ocupações de terrenos públicos ou privados, exerceram pressões sobre o Estado e atuaram como agentes produtores do seu próprio espaço.

Por fim, observa-se que com a implantação do Projeto de Recuperação Ambiental e Urbanização do Bairro Seminário, faz-se necessário a elaboração de estudos referentes aos impactos da referida obra sobre as famílias diretamente afetadas, bem como em relação ao processo de valorização das terras próximas aos locais de intervenção e suas consequências para a população.

\section{REFERÊNCIAS}

BAHIANA, L. C. C. Agentes modeladores e uso do solo urbano. In: Anais do Encontro Nacional dos Geógrafos - Fortaleza. São Paulo, Associação dos Geógrafos Brasileiros, 1978. p. 53-62

BRITO, R. F. de A.; DEUS, J. B. de. A interferência da gestão municipal na produção do espaço, Boletim Goiano de Geografia, Goiânia, v. 29, n. 1, p. 107-120, 2009.

CEARÁ. Governo do Estado. Projeto Executivo - Plano de Reassentamento Involuntário. Março 2013.

CEARÁ. Governo do Estado. Projeto Executivo de Recuperação Ambiental e Urbanização do Bairro Seminário. Setembro, 2010.

CERNEA, M; \& MCDOWELL, C. Risks and reconstruction: experiences of resettlers and refugees. Washington, DC: World Bank, 2000.

CORRÊA, R. L. Sobre agentes sociais, escala e produção do espaço: um texto para discussão. In: CARLOS, A. F; SOUZA, M. L. de; SPOSITO; M. E. B. (org.) A produção do espaço urbano: agentes e processos, escalas e desafios. São Paulo: Contexto, 2014, p. 41-51.

. Trajetórias geográficas. Rio de Janeiro: Bertrand Brasil, 1997. . O espaço urbano. São Paulo: Ática, 1989.

CRATO. Prefeitura Municipal. Plano Diretor Municipal. 2005. 
DOS ANJOS, K. L.; LACERDA, N. Transformações urbanas e ambientais em áreas pobres da Região Metropolitana de Recife (Brasil), Ambiente \& Sociedade, São Paulo, v. XVIII, n.1. p. 41-64. Jan-mar. 2015.

DURAND-LASSERVE, A. L'exclusion des pauvres dans les villes du Tiers Monde. Paris, L'Harmattan, 1996.

FARIAS FILHO, W. A. de. Crato: evolução urbana e arquitetura: 1740-1960. Fortaleza: Expressão Gráfica e Editora, 2007.

FIGUEIREDO FILHO, J. de.; PINHEIRO, I. A cidade do Crato. Min. da Educação e Cultura, 1953.

GIL, A. C. Como elaborar projetos de pesquisa. 5. ed. São Paulo: Atlas, 2010.

HAESBAERT, R. A noção de rede regional: reflexões a partir da migração "gaúcha" no Brasil. Revista Território, ano 3, n. 4, 1998.

HARVEY, D. Alternativas ao neoliberalismo e o direito à cidade. Novos Cadernos NAEA, Belém, v. 12, n. 2, p. 269-274, dez. 2009.

IBGE (Org.). Coordenação de População e Indicadores Sociais. 2014. Disponível em:<http://cidades.ibge.gov.br/xtras/perfil.php?lang=\&codmun=230420\&search=ceara|crato $>$ . Acesso em: 01 set. 2015.

IPECE. Perfil Básico Municipal. 2015. Disponível em: <http://www.ipece.ce.gov.br/publicacoes/perfil_basico/perfil-basico-municipal 2015>. Acesso em: 12 jan. 2015.

IPECE. Perfil Básico Regional. 2009. Disponível em: <http://www2.ipece.ce.gov.br/estatistica/perfil_regional/Perfil_Regional_R9.pdf>. Acesso em: 13 fev. 2015.

LEFEBVRE, H. A. Cidade e o urbano. In: Espaço e política. Belo Horizonte: Editora UFMG, 2008, p. 79-88.

A revolução urbana. Belo Horizonte: Editora UFMG, 1999.

MAIA. H. Memória Histórica do Crato. Identidade. 2014. Disponível em: <https://www.facebook.com/292529590877963/photos/a.307985662665689.1073741852.292 529590877963/415648478566073/?type=3\&theater $>$. Acesso em: 07 jan. 2016.

MONTE-MÓR, R. L. O que é o urbano, no mundo contemporâneo. Revista Paranaense de Desenvolvimento, Curitiba, n. 111, p. 09-18, 2006. 
MOREIRA, G. L.; TREVIZAN, S. D. P. O processo de (re)produção do espaço urbano e as transformações território-ambientais: um estudo de caso, Estudos Geográficos, Rio Claro, v. 3, n. 2, p. 78-90, 2005.

OLIVEIRA FILHO, J. C. A.; MITIDIERO JUNIOR, M. A. Igreja e Movimentos Sociais: O Papel das CEB'S e a Luta pela Moradia na Cidade do Crato - Ceará. Revista Movimentos Sociais e Dinâmicas Espaciais, Recife, v. 03, n. 02, 2014.

PROEMA. Relatório de Impacto Ambiental - RIMA. Relatório de impacto sobre o meio ambiente - recuperação ambiental e urbanização do bairro Seminário. Disponível em: <http://www.semace.ce.gov.br/2012/06/recuperacao-ambiental-e-urbanizacao-do-bairroseminario/>. Acesso em: 25 ago. 2014.

RIBEIRO, S. C; GUERRA, A. J. T. Fatores socioambientais na aceleração de processos erosivos em áreas urbanas: o bairro Seminário, Crato/CE. Revista do Departamento de Geografia - Geo UERJ, n. especial, p. 1827-1829, 2003.

SEABRA, O; CARVALHO, M; LEITE, J.C. Território e sociedade: entrevista com Milton Santos. São Paulo: Fundação Perseu Abramo, 2000.

SILVA; E. P. da. PEREIRA; M. F. G. Análise da formação do bairro Seminário em CratoCE. Fortaleza: Instituto da Memória do Povo Cearense, 2005.

SOUZA, M. J. L. de. O território: sobre espaço e poder, autonomia e desenvolvimento. In: CASTRO, I. E. de. Et al. Geografia, conceitos e temas. 11. ed. Rio de Janeiro: Bertrand Brasil, 2008.

SPOSITO, M. E. B. A produção do espaço urbano: escalas, diferenças e desigualdades socioespaciais. In: CARLOS, A. F. A.; SOUZA, M. L. de; SPOSITO; M. E. B. (org.) A produção do espaço urbano: agentes e processos, escalas e desafios. São Paulo: Contexto, 2014, p. 123-145.

VASCONCELOS, P. de A. Os agentes modeladores das cidades brasileiras no período colonial. In: CASTRO, I. E. de; GOMES, P. C. da C.; CORRÊA, R. L. (org.). Explorações Geográficas: percursos no fim do século. Rio de Janeiro: Bertrand Brasil, 1997, p. 247-278. YIN, R.K. Estudo de caso: planejamen 